\title{
Who provides GP after-hours care?
}

\author{
Mai Pham*, Ian McRae \\ Australian Primary Health Care Research Institute, The Australian National University, Cnr Mills and Eggleston Roads, Acton, \\ Canberra 2601, ACT, Australia
}

\section{A R T I C L E I N F O}

\section{Article history:}

Received 17 September 2013

Received in revised form 8 January 2015

Accepted 8 January 2015

\section{Keywords:}

GP

After-hours

Health services

\begin{abstract}
A B S T R A C T
Understanding the demographic and financial factors likely to influence the supply side of after-hours GP care is crucial in meeting the increasing demand for these services. This study answers two questions: which GPs are more likely to provide after-hours GP care, and of those who do, which are more likely to take a heavier load. Data from the first wave of the Medicine in Australia: Balancing Employment and Life (MABEL) survey is used, with logistic regression applied to address the decision to undertake after-hours work and linear regression to address the question of the quantum of work. The results show that female, older, and urban GPs are less likely to work outside of normal hours. GPs who are employees are less likely to participate in after-hours work than GPs who are principals or partners of a practice. On the other hand, principals and partners, are likely work more hours in the after-hours period than employee GPs if they do participate in this work. Similarly, those GPs in solo practice who work after-hours also tend to take a heavier after-hours workload than the GPs who are not in solo practice. The role of GP wages and family income does not seem to be compelling. These conclusions are likely to relate to the ways doctors behave independent of the health system.
\end{abstract}

(c) 2015 Elsevier Ireland Ltd. All rights reserved.

\section{Introduction}

After-hours GP care has gained considerable attention from patients, primary care organizations, medical associations and policy makers around the world in recent years. In many countries there are concerns about the accessibility, quality and efficiency of these services. Significant effort has been devoted to the development and the implementation of different organizational models of after-hours care provision, with diverse models being applied in different countries $[1,2]$.

One aspect of provision of after-hours care which has not been much addressed in the literature is the behavior

\footnotetext{
* Corresponding author. Tel.: +61 026125 5499; fax: +61 262300525. E-mail addresses: mai.pham@anu.edu.au (M. Pham), ian.s.mcrae@anu.edu.au (I. McRae).
}

of GPs themselves, and examination of which groups of GPs offer after-hours care. The exodus of UK GPs from providing this care after the 2004 reforms [3] and news reports in 2013 that $60 \%$ of GPs would consider resigning rather than return to providing after-hours care [4] emphasize the difficulties health systems face in providing such care. These issues are magnified in most countries by the fact that female GPs are generally less likely to provide after-hours care, but the proportions of female GPs are steadily increasing. While health systems influence GPs decisions, an understanding of which groups are most likely to provide this care and which are not is of relevance to all systems.

Some previous studies examine the supply of GP afterhours care services as part of investigations of GP labor supply. Riddell (1980) concludes that compared with doctors in solo practice, doctors in a group of three or four are better able to cover their out-of hours [5]. Livingstone et al. suggest that doctors need to live near their practice 
and need a financial reward to be willing to provide outof-hour services [6]. Lattimer et al. find that most GPs hope to reduce or opt out of their on call commitments, with the urban GPs more likely than rural GPs have this hope [7]. Giuffrida and Gravelle find single handed GPs and older GPs make fewer out-of-hours night visits, GPs in areas with higher population density make more visits and GPs are responsive to an increase in fees [8]. Wordsworth et al. conclude all GPs, regardless of their contract status, would prefer to work less after-hours and would opt out if the remuneration was too low [9]. While these studies all relate to the United Kingdom, more recent European studies find addressing structural issues find that GPs after-hours workload is significantly reduced if they participate in large scale after-hours cooperatives rather than individual or small local practices $[1,10]$.

This study examines factors associated with likelihood of working after-hours and with after-hours workloads of general practitioners in Australia. Since Australia shares many common health care features with other Western countries, this study will be relevant to understanding the after-hours GP market beyond Australia.

\subsection{Australian government and GP after-hours provision}

Traditionally, after-hours care was mainly provided by GPs to their own patients [11], but from the late 1960s the trend away from this structure began with the use of deputizing services. The provision of after-hours care has followed different pathways in different countries, including the use of small co-operatives, large co-operatives and telephone triage [1], but all depend on GPs being willing to work unsociable hours. GPs in Australia are increasingly moving away from solo practice and utilizing alternative methods to cover after-hours care [12]. In response to increasing demand for GP after-hours care [13], the Australian government has implemented a range of reforms to expand and improve after-hours GP service provision [14].

The Australian government has introduced three major after-hours care programs. The After Hours Primary Medical Care Program (AHPMC) was a four-year program in the early 2000s which provided grants and funding to improve services in local communities, including funding to advance quality of Medical Deputising Services (MDS). In 2004, The Round the Clock Medicare: Investing in After Hours GP Services (IAHGPS) program supported the growth of after-hours general practice and aimed to encourage the development of new after-hours services [15]. In 2006, the Council of Australian Governments (COAG) established the National Health Call Centre Network, which aimed to provide access to health care information and advice $24 \mathrm{~h}$ per day, seven days per week $[16,17]$.

In association with these programs and grants, the Australian government also introduced items into Medicare, the national health insurance scheme, for non-urgent after-hours attendances and increased rebates for urgent after-hours attendances. Medicare provides subsidies known as rebates to patients for all private medical services in Australia, with the size of the rebates dependent on the service provided. Doctors may choose to accept the rebate as full payment (referred to as bulk billing) or may charge above the level of the rebate, with patients paying a "fee gap" out of pocket. For example, the rebate for a standard GP consultation is $\$ 37.05$, and if a GP charged $\$ 70$ the patient would pay a gap of $\$ 32.95$ out of pocket. Prior to January 2005, after-hours services were only differentiated from in-hours for emergency afterhours attendances. From January 2005, new items were introduced explicitly for after-hours consultations with rebates $\$ 10$ higher than the standard hours consultation rebates $[18,19]$.

In addition, the Australian government provided incentives to GP practices for arranging after-hours coverage for their patients through the Practice Incentives Program (PIP), a program of payments to practices separate from the fee for service arrangements which aimed to support GPs for improvement to patient access and quality of care. In February 2013, 5035 of the 7000 approximately practices received PIP payments. Of those receiving PIP payments $55.6 \%$ were directly involved in the provision of after-hours care (at least $15 \mathrm{~h}$ per week), and around $25 \%$ indicated that they provided all the afterhours care for their patients [20]. PIP after-hours incentive payments ended in June 2013, with funding transferred to Medical Locals which are primary health care organizations designed to improve health care access and delivery including after-hours care. It was considered that local knowledge would improve organization of and access to after-hours care [21]. Each of the 61 Medicare Locals has been provided with funding to compile local after-hours service directories, to arrange local oncall rosters and to fund local GPs to expand their hours [22].

These initiatives show the policy focus on GP provision of after-hours services, which are defined in Australia as between $6 \mathrm{pm}$ and 8 am on weekdays, from 12 noon on Saturdays, and full day on Sundays and public holidays [23]. These services are mainly provided by long hours GP practices, GPs on call from their practice on a roster basis or by GPs in MDS. In 2009, the GP practice based services and MDS provision share was estimated to be around $77 \%$ of all after-hours services including hospital emergency departments [24].

A crucial aspect in promoting after-hours care is identifying GPs who are likely to provide the services. Understanding factors influencing GPs' decisions to provide after-hours care will provide valuable information for primary health care organizations and policy makers. However, the current authors can identify no study examining how personal, family and work characteristics are reflected in GP's decisions to provide after-hours care. Many previous studies investigate GP labor demand and supply [25-29]. The few studies of after-hour GP services tend to focus on demand. This study aims to contribute to the development of after-hours GP services by investigating the supply side of the market. It examines the factors associated with two decisions by GPs: whether or not to provide after-hours care and how many hours to provide when they do provide the service. The study is organized as follows: Section 2 provides a description of data and variables, Section 3 discusses the methods used, descriptive and regression analysis results are presented in Section 4 
and Section 5 discusses the results and limitations of the study.

\section{Data and variables}

\subsection{Data}

The study uses data from the survey of Medicine in Australia: Balancing Employment and Life (MABEL). Conducted by researchers at the Melbourne Institute of Applied Economics and Social Research and Monash University, MABEL is a large scale longitudinal survey which contains information about workload, workplace and some financial, family and demographic information for a cohort of Australian doctors. Five waves of data have been released (collected in 2008, 2009, 2010, 2011, and 2012) [30]. This study uses data for the 3906 GPs included in the first wave of the survey. Although, longitudinal analysis would have been preferable, changes in the questions over time limit the capacity to follow changes in GP after-hours work.

\subsection{Variables}

\subsubsection{Measurement of after-hours care}

Responding GPs, who report that they undertake any after-hours or on call work are considered to have decided to provide after-hours care. For those actually providing care (i.e. with more than zero hours provided outside normal hours) only hours of direct after-hours patient care is considered.

\subsubsection{Individual characteristics and family situation}

Individual characteristics include demographic features such as gender, age and origin of a GP's medical degree (overseas or Australia) while family situation reflects the number of dependent children. Gender and having a dependent child aged less than five years are represented by indicator variables. Age is included in the form of indicator variables for five different age groups, which allows non-linear association with the after-hours variables. The number of dependent children is also explored using indicator variables.

\subsubsection{Workplace and employment characteristics}

Three workplace features are examined: location, type of practice, and GP relationship with practice. Location of practice is major city, inner regional area, or "outer" area comprising outer regional/remote/very remote areas [31]. Type of practice is solo or non-solo. The GP's relationship with their practice are categorized as ownership (including principals and partners), employee groups classified as associates, salaried, contract employees and locums, together with "other GPs".

\subsubsection{Financial situation}

Three financial measures are examined: the amount of other income within the GP's family (net household income less the GP's reported net medical income), GP's partner's employment status, and the percentage of patients the GP reports they bulk-bill (under bulk billing, the GP receives payment directly from Medicare Australia and no gap payment is permitted to be charged of the patient).

\subsubsection{Average hourly earnings}

The price of GP labor is expected to have significant impact on GP labor supply. Ideally, in-hours and after-hours earnings rates would be included separately in the modeling. However, given the structure of the MABEL data it is only possible to estimate the overall hourly rate using total medical income and total medical hours (estimated from the number of weeks worked - subtracting weeks of leave and other weeks not working from 52 - and the usual total hours worked per week). If overall average hourly earnings rate is a good proxy for the after-hours wage rate, this would be expected to be positively associated with the after-hours work. However, it may have no measurable impact if there is a significant difference between afterhours earnings and overall average hourly earnings.

\subsubsection{Interaction terms}

The impact of having a young dependent child on work patterns may be different for male and female GPs since female GPs are likely to be spending more time on looking after children than male GPs. Further, as many overseas trained GPs are obliged to work in rural areas for a period when first working in Australia, the impacts of rurality on GPs trained inside and outside Australia are likely to be different. To accommodate these relationships interaction terms between GP gender and the presence of young dependent children, and between origin of medical degree and remoteness of practice, are included in order to control for the likelihood that combined effects of the interacting variables are different to the sum of the separate effects.

\section{Methods}

Two sets of multivariate regression models are estimated. The first set uses logistic regression to model the probability of participating in after-hours work, while the second uses linear regression to model the weekly hours of after-hours work for those who do participate. The same three groups of independent variables are used in both sets of models. Model 1 includes individual, family and work features, model 2 adds financial features and model 3 adds hourly earnings rate. The separation between models 2 and 3 is due to the uncertainty about suitability of hourly earnings rate as a proxy for after-hours wage rate. In all three models, associations rather than causations between dependent and independent variables are examined as the direction of causality is not clear for a number of variables-for example, the overall income available will influence decisions in relation to after-hours work but after-hours work will influence income, and arguably while number of children influences work hours, after-hours work decisions may also influence decisions on family size.

As there is significant non-response to the income variables, the samples available for models 2 and 3 are substantially smaller than those for model 1 . Differences between models may, therefore, be due to the impact of additional variables or the changing sample, either due to 
reduced power from the smaller samples or due to response biases.

\section{Results}

\subsection{Descriptive results}

Table 1 presents summary statistics for variables included in the regression models. As 39\% of male GPs and $23 \%$ of female GPs provide after-hours care, male GPs are more likely to provide after-hours care. On average they also undertake a heavier workload than female GPs (7.3 h compared with $6 \mathrm{~h}$ per week). Those aged 50-59 years are generally more likely to work after-hours than the older or younger groups (37.8\% compared to $32.2 \%$ or less), with those in the 40-49 years age range who work after hours likely to provide the most hours. GPs in regional areas are more likely to undertake after hours work, with $55.4 \%$ in inner regional and $48.3 \%$ in outer regional areas providing services in these hours while $26.2 \%$ in major cities do so.

There is no difference in the proportion of GPs working after-hours between solo and non-solo practice, although on average GPs in solo practices who do work after-hours provide more hours. A larger percentage of principals and associates participate in after-hours service than practice employees, but locums provide substantially more afterhours care on average than other GPs. GPs graduating in Australia are marginally more likely to participate in afterhours care than those graduating overseas although on average, the former group supplies less after-hours service.

After hours work is less likely when partners are in full time work, but hours provided are less if the partner undertakes any work than if they are not working. While non-medical income is negatively associated with the percentage of GPs undertaking after-hours work, its association with after-hours workload is unclear. In contrast, there is no clear association between GPs participation in after-hours care and their percentage of bulk-billed patients or their average hourly earnings, although the hours provided appear to have a positive association with these factors.

\subsection{Modeling results}

Results for logistic and linear regressions are presented in Tables 2 and 3. The results in Table 2 are shown as odds ratios, which indicate a negative association between the dependent variable and independent variable if the value is less than unity, and a positive association if the value is more than unity. For example, with the odds ratio of 0.512 for the gender variable, the odds of a female GP participating in after-hours care provision are $51.2 \%$ of the odds of a male GP participating. For convenience, the decision whether or not to participate in after-hours work is referred as the first decision and the decision on how much work a GP provides is referred to as the second decision. Overall, in addition to the effects of gender, age and rurality which could be expected, the other consistently strong effect is that employed GPs and contract GPs are less likely to work after hours than practice principals or partners, with odds ratios of around 0.5 .
Table 2 shows results of the logistic regression exploring who works after-hours. Across all three models, female GPs are less likely to undertake after-hours work than their male counterparts. GPs aged 60 or older are less likely to undertake after-hours work than most of younger groups. GPs whose practices are in inner regional or outer areas are more likely to provide after-hours services than those in major cities. Compared with practice owners or partners, employed GPs are less likely to undertake after-hours work. A statistically significant and positive association between the first GP after-hours work decision and the percentage of bulk-billed patients and hourly earnings, and a negative association with non-medical income can be found in both models 2 and 3, however, odds ratios very near 1 indicate that the impact is small. GP's partner's employment situation and the origin of GPs medical degree are not significantly related to their first after-hours care decision. The introduction of financial factors into the models has a minimal impact on the odds ratios for other variables.

Table 3 shows results of the linear regression which explores the number of hours of after-hours care per week provided by GPs who work after-hours. Gender has the most significant impact when financial factors, and most notably the hourly wage, are excluded. GPs in age groups 40-49 years appear to provide longer hours of afterhours care. The combination of being female and having a youngest child aged less than five has a negative and significant impact on hours provided. GPs whose practice is located in a regional area, especially in outer areas, provide significantly more hours of after-hours service than their urban counterparts. While GPs in solo practice are somewhat less likely than other GPs to participate in after-hours (Table 2), once they do, they appear to take a heavier workload than their colleagues in non-solo practice. While locums work significantly longer after-hours than other GPs, this effect is not significant after allowing for financial factors. Contracted employees working after-hours provide significantly more hours than practice owners, although only $1.6 \mathrm{~h}$ per week on average. Financial factors have the expected signs but are not statistically significant.

\section{Discussion of results}

GPs appear to react differently to the two after-hours work decisions. Female GPs are less likely to undertake after-hours work than their male colleagues, however, once female GPs decide to participate in after-hours work, their commitment is no different to that of male GPs after allowing for financial effects, most prominently the hourly wage where the average female hourly wage is $12 \%$ below that of males. Conversely, while having a child aged less than five may reduce a female GP's after-hours workload, it does not appear to influence their decision to participate in afterhours work when all other factors are accommodated.

Older GPs, especially those 60 years of age and older, are less likely to participate in after-hours work than their younger colleagues. This may be due to the different stages in their careers or perception about work-life balance. The relatively low likelihood of older GPs undertaking afterhours work is broadly aligned with Giuffrida and Gravelle [8] who find older GPs make fewer night visits. On the other 
Table 1

Descriptive statistics of variables.

\begin{tabular}{|c|c|c|c|}
\hline & $\begin{array}{l}\text { Percentage of total } \\
\text { respondents in } \\
\text { each group (\%) }\end{array}$ & $\begin{array}{l}\text { Percentage of GPs } \\
\text { doing AH work in } \\
\text { each group (\%) }\end{array}$ & $\begin{array}{l}\text { Average AH } \\
\text { workload in each } \\
\text { group }\end{array}$ \\
\hline Groups & & & (Hours/week) \\
\hline Total & & 32.8 & 6.98 \\
\hline \multicolumn{4}{|l|}{ Gender } \\
\hline Male & 61.4 & 39.0 & 7.34 \\
\hline Female & 38.6 & 23.0 & 6.01 \\
\hline \multicolumn{4}{|l|}{ Age groups } \\
\hline Age under 40 years & 18.6 & 30.7 & 6.55 \\
\hline Age $40-49$ years & 30.3 & 32.2 & 7.76 \\
\hline Age $50-59$ years & 34.7 & 37.8 & 6.80 \\
\hline Age group 60-69 years & 12.2 & 32.0 & 6.60 \\
\hline Age group70 years and above & 4.3 & 20.2 & 5.62 \\
\hline \multicolumn{4}{|l|}{ Number of dependent children } \\
\hline 0 & 33.1 & 31.7 & 5.05 \\
\hline 1 & 15.2 & 35.3 & 5.42 \\
\hline 2 & 28.0 & 32.0 & 5.50 \\
\hline 3 Or more & 23.8 & 40.2 & 6.06 \\
\hline \multicolumn{4}{|l|}{ Youngest child $<5$ years } \\
\hline Yes & 22.7 & 30.3 & 7.55 \\
\hline No & 77.3 & 37.3 & 7.47 \\
\hline \multicolumn{4}{|l|}{ Location of practice } \\
\hline Major city & 72.3 & 26.2 & 6.05 \\
\hline Inner regional & 18.5 & 48.3 & 6.79 \\
\hline Outer regional & 9.2 & 55.4 & 10.34 \\
\hline \multicolumn{4}{|l|}{ Practice type } \\
\hline Solo practice & 11.0 & 33.0 & 8.80 \\
\hline Non solo practice & 89.0 & 33.7 & 6.77 \\
\hline \multicolumn{4}{|l|}{ Relationship with practice } \\
\hline Principal or partner & 35.3 & 42.4 & 6.22 \\
\hline Associate & 11.3 & 40.6 & 7.04 \\
\hline Salaried employee & 7.5 & 32.1 & 7.24 \\
\hline Contracted employee & 40.4 & 24.5 & 7.34 \\
\hline Locum & 2.5 & 26.3 & 14.85 \\
\hline Other & 3.0 & 35.6 & 8.08 \\
\hline \multicolumn{4}{|l|}{ Complete medical degree } \\
\hline Overseas & 26.1 & 29.6 & 7.51 \\
\hline Australia & 74.0 & 34.0 & 6.79 \\
\hline \multicolumn{4}{|l|}{ Other income } \\
\hline Yes & 53.8 & 33.6 & 6.90 \\
\hline No & 46.2 & 34.5 & 7.07 \\
\hline \multicolumn{4}{|l|}{ Partner employment } \\
\hline Not in the labor force & 19.2 & 39.2 & 7.85 \\
\hline Currently seeking work & 1.9 & 27.5 & 7.95 \\
\hline Full time employment & 38.2 & 29.0 & 6.81 \\
\hline Part time employment & 27.6 & 41.2 & 6.45 \\
\hline Not applicable & 13.1 & 29.1 & 7.09 \\
\hline \multicolumn{4}{|l|}{ Percentage of bulk-billed patients } \\
\hline 1st Quintile & 23.4 & 28.6 & 5.75 \\
\hline 2nd Quintile & 17.3 & 35.2 & 6.13 \\
\hline 3rd Quintile & 21.6 & 41.8 & 6.25 \\
\hline 4th Quintile & 17.1 & 37.7 & 8.46 \\
\hline 5th Quintile & 20.6 & 29.5 & 8.61 \\
\hline \multicolumn{4}{|l|}{ Non-medical income } \\
\hline 1st Quintile & 26.0 & 40.3 & 7.88 \\
\hline 2nd Quintile & 16.7 & 38.3 & 6.06 \\
\hline 3rd Quintile & 19.2 & 38.2 & 6.83 \\
\hline 4th Quintile & 18.1 & 36.1 & 5.34 \\
\hline 5th Quintile & 20.0 & 28.3 & 6.66 \\
\hline \multicolumn{4}{|l|}{ Earning (hourly rate) } \\
\hline 1st Quintile & 20.1 & 34.2 & 6.18 \\
\hline 2nd Quintile & 18.8 & 28.3 & 5.71 \\
\hline 3rd Quintile & 20.9 & 33.3 & 6.66 \\
\hline 4th Quintile & 20.0 & 34.6 & 7.84 \\
\hline 5th Quintile & 20.1 & 43.2 & 8.42 \\
\hline
\end{tabular}

Note: the first quintile in each case refers to the lowest value of the variable e.g. the lowest bulk billing rates. The Quintiles are not uniformly $20 \%$ due to the rounding of responses by respondents leading to "heaping" which leads to all observations in the "heap" being attributed to one quintile and this value then becoming greater than $20 \%$ and other values of necessity less than $20 \%$. 
Table 2

Likelihood of working after-hours.

\begin{tabular}{|c|c|c|c|}
\hline & Model 1 & Model 2 & Model 3 \\
\hline & OR(95\%CI) & OR(95\%CI) & OR(95\%CI) \\
\hline Male & 1.000 (Reference) & 1.000 (Reference) & 1.000 (Reference) \\
\hline Female & $0.512(0.431-0.607)^{* * *}$ & $0.590(0.458-0.760)^{* * *}$ & $0.614(0.469-0.804)^{* * *}$ \\
\hline Age under 40 years & 1.000 (Reference) & 1.000 (Reference) & 1.000 (Reference) \\
\hline Age $40-49$ years & $0.816(0.636-1.047)$ & $0.822(0.584-1.156)$ & $0.872(0.608-1.252)$ \\
\hline Age $50-59$ years & $0.901(0.699-1.162)$ & $0.777(0.548-1.103)$ & $0.838(0.578-1.214)$ \\
\hline Age $60-69$ years & $0.712(0.523-0.967)^{* *}$ & $0.632(0.413-0.967)^{* *}$ & $0.567(0.360-0.894)^{*}$ \\
\hline Age 70 years and above & $0.390(0.241-0.630)^{* * * *}$ & $0.332(0.165-0.669)^{* * * *}$ & $0.347(0.169-0.711)^{* *}$ \\
\hline No youngest child $<5$ & 1.000 (Reference) & 1.000 (Reference) & 1.000 (Reference) \\
\hline Youngest child $<5$ & $0.936(0.693-1.265)$ & $0.913(0.600-1.388)$ & $0.877(0.562-1.368)$ \\
\hline No dependent children & 1.000 (Reference) & 1.000 (Reference) & 1.000 (Reference) \\
\hline Dependent children (1) & $1.127(0.885-1.436)$ & $0.901(0.644-1.261)$ & $0.811(0.566-1.162)$ \\
\hline Dependent children (2) & $1.005(0.812-1.244)$ & $0.921(0.680-1.249)$ & $0.828(0.600-1.142)$ \\
\hline Dependent children (3+) & $1.168(0.93-1.465)$ & $0.936(0.672-1.304)$ & $0.911(0.643-1.291)$ \\
\hline Female \& youngest child < 5 & $0.809(0.542-1.209)$ & $0.798(0.449-1.417)$ & $0.864(0.468-1.596)$ \\
\hline Major city & 1.000 (Reference) & 1.000 (Reference) & 1.000 (Reference) \\
\hline Inner regional & $2.320(1.898-2.837)^{* * *}$ & $2.439(1.840-3.232)^{* * *}$ & $2.499(1.855-3.368)^{* * *}$ \\
\hline Outer regional & $3.599(2.804-4.620)^{* * *}$ & $3.531(2.496-4.995)^{* * * *}$ & $3.484(2.419-5.018)^{* * *}$ \\
\hline Non-solo practice & 1.000 (Reference) & 1.000 (Reference) & 1.000 (Reference) \\
\hline Solo practice & $0.793(0.618-1.019)^{*}$ & $0.757(0.537-1.067)$ & $0.786(0.545-1.132)$ \\
\hline Principal or partner & 1.000 (Reference) & 1.000 (Reference) & 1.000 (Reference) \\
\hline Associate & $0.849(0.667-1.081)$ & $0.844(0.601-1.186)$ & $0.852(0.596-1.217)$ \\
\hline Salaried employee & $0.587(0.441-0.782)^{* * *}$ & $0.500(0.333-0.751)^{* * * *}$ & $0.454(0.291-0.709)^{* * *}$ \\
\hline Contracted employee & $0.493(0.41-0.593)^{* * *}$ & $0.489(0.378-0.633)^{* * *}$ & $0.501(0.382-0.657)^{* * *}$ \\
\hline Locum & $0.580(0.336-1.000)$ & $0.876(0.400-1.917)$ & $0.763(0.336-1.730)$ \\
\hline Others & $0.989(0.638-1.531)$ & $1.116(0.600-2.075)$ & $1.077(0.567-2.044)$ \\
\hline Australian Med degree & 1.000 (Reference) & 1.000 (Reference) & 1.000 (Reference) \\
\hline Overseas Med degree & $0.835(0.657-1.063)$ & $0.875(0.619-1.238)$ & $0.909(0.628-1.315)$ \\
\hline Inner reg \& overseas degree & $1.128(0.744-1.709)$ & $1.084(0.604-1.944)$ & $1.061(0.574-1.962)$ \\
\hline Outer reg \& overseas degree & $1.084(0.702-1.673)$ & $0.815(0.439-1.511)$ & $0.795(0.416-1.519)$ \\
\hline Partner not working & 1.000 (Reference) & 1.000 (Reference) & 1.000 (Reference) \\
\hline Partner working & & $1.156(0.888-1.506)$ & $1.178(0.893-1.555)$ \\
\hline Partner N/A & & $0.987(0.68-1.432)$ & $0.951(0.643-1.406)$ \\
\hline Percentage bulk-billed & & $1.004(1.000-1.007)^{* *}$ & $1.004(1.001-1.008)^{* *}$ \\
\hline Non- medical income & & $0.997(0.994-0.999)^{* *}$ & $0.996(0.994-0.998)^{* *}$ \\
\hline Wage (hourly rate) & & & $1.001(1.000-1.002)$ \\
\hline Constant & $0.857(0.648-1.134)$ & $0.871(0.542-1.401)$ & $0.756(0.448-1.276)$ \\
\hline Number of observations & 3688 & 1855 & 1656 \\
\hline Log likelihood & -2168 & -1118 & -998 \\
\hline
\end{tabular}

hand, while GPs aged 40-49 who work after-hours provide the greatest number of hours, the other age groups are not significantly different from each other. Other studies suggest solo GPs are less likely to provide after-hours care [8] because it is easier for large practices to share such work among themselves. While the solo GPs in our study are less likely to provide such care, the effect is not significant, but those who do provide after-hours care tend to provide more of these hours.

As the number of GPs in regional areas is insufficient to meet demand [32], the significant provision of after-hours care by GPs in these areas is likely to be caused by demand-pull. In many rural areas the GP provides after-hours medical care which can be provided in the local hospital as well as in the surgery or the community. The GPs after-hours activity, therefore, can be quite different to the activity of the urban GPs. While driven by demand rather than supply, this is consistent with the findings of Lattimer et al. [7] who found urban GPs were more likely to hope to reduce their after-hours commitment.
Practice principals may consider after-hours work as an extension of their in-hours work and hence be more likely to participate in this work than their employees, but be less heavily involved. The heavy involvement of contracted GPs with after-hours work may be taking an opportunity to increase income and to make up for job instability, but in many cases will be structural with principals, corporate practices, and medical deputizing services contracting GPs to fill after-hours roles.

Financial factors including the percentage of bulk billed patients and non-medical income are significantly associated with the first after-hours decision. However, no solid conclusion can be drawn due to the relatively small impact (reflected by odds ratios close to 1) and potential twoway causality (e.g. GPs with a high percentage of bulk billed patients may have lower income and so be more likely to work after-hours for extra income, but alternatively GPs who have income from after-hours work may be more likely to bulk bill patients). The potential income effects (i.e. whether GPs supply less after-hours services if they have income from alternate sources) can be seen 
Table 3

Hours of after-hours provision.

\begin{tabular}{|c|c|c|c|}
\hline & Model 1 & Model 2 & Model 3 \\
\hline & Coefficient (95\% CI) & Coefficient (95\% CI) & Coefficient (95\% CI) \\
\hline Male & 1.000 (Reference) & 1.000 (Reference) & 1.000 (Reference) \\
\hline Female & $-1.531(-2.667-0.395)^{* *}$ & $-1.220(-2.630-0.191)^{*}$ & $-0.515(-1.980-0.950)$ \\
\hline Age under 40 years & 1.000 (Reference) & 1.000 (Reference) & 1.000 (Reference) \\
\hline Age $40-49$ years & $1.290(-0.162-2.742)^{*}$ & $2.245(0.292-4.198)^{*}$ & $2.462(0.392-4.531)^{*}$ \\
\hline Age $50-59$ years & $0.322(-1.181-1.824)$ & $1.022(-0.913-2.957)$ & $1.043(-0.979-3.065)$ \\
\hline Age $60-69$ years & $-0.571(-2.455-1.313)$ & $0.638(-1.797-3.073)$ & $0.184(-2.030-2.397)$ \\
\hline Age 70 years and above & $-0.738(-4.010-2.534)$ & $1.506(-3.384-6.396)$ & $1.256(-3.680-6.191)$ \\
\hline No youngest child $<5$ & 1.000 (Reference) & 1.000 (Reference) & 1.000 (Reference) \\
\hline Youngest child $<5$ & $0.177(-1.807-2.162)$ & $2.067(-0.971-5.106)$ & $2.161(-1.096-5.417)$ \\
\hline No dependent children & 1.000 (Reference) & 1.000 (Reference) & 1.000 (Reference) \\
\hline Dependent children (1) & $0.010(-1.557-1.578)$ & $0.122(-1.693-1.937)$ & $0.083(-1.968-2.133)$ \\
\hline Dependent children (2) & $0.507(-0.857-1.872)$ & $1.381(-0.233-2.994)$ & $1.136(-0.570-2.843)$ \\
\hline Dependent children $(3+)$ & $1.005(-0.475-2.485)$ & $1.191(-0.714-3.096)$ & $1.397(-0.622-3.417)$ \\
\hline Female \& youngest child < 5 & $-1.437(-3.596-0.722)$ & $-2.823(-6.005-0.359)^{*}$ & $-3.356(-6.875-0.163)^{*}$ \\
\hline Major city & 1.000 (Reference) & 1.000 (Reference) & 1.000 (Reference) \\
\hline Inner regional & $0.360(-0.782-1.503)$ & $1.272(-0.246-2.789)$ & $1.604(-0.009-3.216)^{*}$ \\
\hline Outer regional & $3.469(1.779-5.159)^{* * *}$ & $2.986(0.806-5.167)^{* *}$ & $3.072(0.748-5.395)^{* *}$ \\
\hline Non-solo practice & 1.000 (Reference) & 1.000 (Reference) & 1.000 (Reference) \\
\hline Solo practice & $3.000(0.831-5.168)^{* *}$ & $2.169(-0.345-4.683)^{*}$ & $2.942(0.178-5.705)^{* *}$ \\
\hline Principal or partner & 1.000 (Reference) & 1.000 (Reference) & 1.000 (Reference) \\
\hline Associate & $1.088(-0.367-2.542)$ & $1.372(-0.698-3.441)$ & $1.169(-1.015-3.353)$ \\
\hline Salaried employee & $0.876(-0.781-2.533)$ & $1.220(-1.029-3.470)$ & $1.004(-1.555-3.563)$ \\
\hline Contracted employee & $1.965(0.700-3.23)^{* *}$ & $2.244(0.585-3.903)^{* *}$ & $1.553(-0.150-3.255)^{*}$ \\
\hline Locum & $6.622(-0.099-13.343)^{*}$ & $0.682(-4.351-5.716)$ & $1.209(-4.667-7.085)$ \\
\hline Others & $3.320(0.272-6.367)$ & $3.502(-0.602-7.607)^{*}$ & $2.432(-1.637-6.501)$ \\
\hline Australian Med degree & 1.000 (Reference) & 1.000 (Reference) & 1.000 (Reference) \\
\hline Overseas Med degree & $-0.276(-1.769-1.217)$ & $0.070(-2.183-2.322)$ & $0.109(-2.074-2.292)$ \\
\hline Inner reg \& overseas degree & $0.704(-1.800-3.207)$ & $-1.017(-4.294-2.261)$ & $-0.897(-4.178-2.384)$ \\
\hline Outer reg \& overseas degree & $-0.122(-3.131-2.886)$ & $0.368(-4.127-4.864)$ & $0.985(-3.662-5.632)$ \\
\hline Partner not working & 1.000 (Reference) & 1.000 (Reference) & 1.000 (Reference) \\
\hline Partner working & & $-0.661(-2.343-1.021)$ & $-0.250(-1.960-1.461)$ \\
\hline Partner N/A & & $-0.075(-2.385-2.235)$ & $-0.116(-2.196-1.964)$ \\
\hline Percentage bulk-billed & & $0.022(-0.001-0.045)^{*}$ & $0.016(-0.009-0.041)$ \\
\hline Non-medical income & & $-0.002(-0.017-0.012)$ & $-0.003(-0.018-0.013)$ \\
\hline Wage (hourly rate) & & & $0.005(-0.004-0.015)$ \\
\hline Constant & $4.692(3.088-6.296)$ & $2.187(-0.342-4.716)$ & $1.576(-1.132-4.285)$ \\
\hline Number of observations & 1314 & 707 & 638 \\
\hline$R$ squared & 0.068 & 0.087 & 0.093 \\
\hline
\end{tabular}

${ }^{*} p<0.1$.

** $p<0.05$.

*** $p<0.001$.

from the odds ratio of less than 1 and the negative sign in the linear regression model for non-medical income. However, since the impact is small, being significant in the first case and not statistically significant in the second case, the income effect does not appear to be important in either of the after-hours decisions for GPs. Odds ratios slightly greater than 1 in the logistic regression model and the positive coefficient of average hourly earnings variable in the linear model regressions (statistically significant only in the logistic model) may signal a weak "substitution" effect where the higher wages encourage GPs to substitute longer work hours for some of their leisure time. Previous studies $[8,9]$ have shown GPs commitment to after-hours work is responsive to financial rewards, and our weaker results may be due to our need to use average wage rates rather than explicit after hours rates in our analysis. If in fact our weak effects are correct then large wage increases would be needed to generate any material change.

This study has some limitations. The dataset does not include information of all doctors in Australia. However, since MABEL has a response rate of $19.36 \%$ of the total Australian doctor population and previous analyses "demonstrate no serious response bias in MABEL with respect to age, gender, geographic location and hours worked" [30], findings from the current study can be applied with some confidence. The absence of separate earnings rates for GP after-hours work, and the need to use average hourly earnings rates as a proxy, may have led to this factor not being statistically significant in linear regression modeling, although it may also indicate that demographic and unmeasured demand variables dominate. As all data are self-reported, despite the endeavors of the data managers to minimize unwelcome effects, they may suffer from reporting errors [33]. The loss of observations due to non-response to income questions has a risk of bias, and reduces the significance of estimates, however, with a few exceptions this seems to have had limited impact on the interpretation of the results.

While the data examined in this study is from 2008 and is five years old, the major reform in this period has been 
the transition of funding to the Medicare Locals, which is too recent to allow any analysis of its impact. We also note that the issues mainly addressed, the role of demography and income on provision of after-hours care are unlikely to have changed over such a relatively short period, and indeed are likely to be able to be extrapolated to other environments.

\section{Conclusion}

The purpose of this study was to identify which groups of GPs are optimal targets when recruiting doctors for after-hours work. While doctors in regional areas are the most likely to participate in after-hours care, and those in outer regional on average provide more hours than any other subgroup, this is more a demand than a supply effect and not immediately relevant to our questions. The study finds minimal significant impact of after-hours wages (noting that the effects are in the expected direction, but the wages are approximated by total hourly wages).

There are of course two approaches targeting GPs for after-hours work, policy could focus on those groups known to provide after-hours care or to provide long hours of after-hours care, or alternately they could focus on groups which rarely provide after-hours care as an opportunity where greater returns could be achieved. The difference in GPs behavior regarding the two after-hours decisions clearly has important policy implications, as efforts could be made to encourage groups to provide any after-hours care, or to encourage those who provide some care to increase their hours.

Overall the study suggests that GPs demographic patterns and work features are significantly related to GPs decision making in relation to after-hours care provision, but the association of financial factors such as other nonmedical income and percentage of bulk-billed patients does not appear to be substantial. As demand for GP afterhours care has increased substantially in most countries and a range of measures have been taken by governments around the world to improve and increase supply, identifying the groups of GPs more likely to provide the service and more likely to take a larger after-hours workload, should inform future policy directions.

\section{Conflict of interest statement}

There is no conflict of interest for this work.

\section{Acknowledgements}

This paper used data from the MABEL longitudinal survey of doctors conducted by the University of Melbourne and Monash University (the Mabel research team). MABEL is funded by the National Health and Medical Research Council and the Department of Health and Ageing, Australian Government. The MABEL research team bears no responsibility for how the data has been analyzed, used or summarized in this paper.

\section{References}

[1] Grol R, Giesen P, Uden C. After-hours care in the United Kingdom, Denmark, and The Netherlands: new models. Health Affairs 2006;25(6):1733-7.

[2] Huibers L, Giesen P, Wensing M, Grol R. Out-of-hours care in western countries: assessment of different organizational models. BMC Health Services Research 2009;9(105).

[3] Richards S, Pound P, Dickens A, Greco M, Campbell J. Exploring users' experiences of accessing out-of-hours primary medical care services. Quality and Safety in Health Care 2007;16:469-77, http://dx.doi.org/10.1136/qshc.2006.021501.

[4] Kaffash J. Six in ten GPs ‘could resign' over out-of-hours proposals Pulse 2013.

[5] Riddell J. Out-of-hours visits in a group practice. British Medical Journal 1980;280:1518-9.

[6] Livingstone A, Jewell J, Robson J. Twenty four hour care in inner cities: two years out of hours workload in east London general practice. British Medical Journal 1989;299:368-70.

[7] Lattimer V, Smith H, Hungin P, Glasper A, George S. Future provision of out of hours primary medical care: a survey with two general practitioner research networks. British Medical Journal 1996;312:312-52.

[8] Giuffrida A, Gravelle H. Inducing or restraining demand: the market for night visits in primary care. Journal of Health Economics 2001;20:755-79.

[9] Wordsworth S, Skatun D, Scott A, French F. Preferences for general practice jobs: a survey of principals and sessional GPs. British Journal of General Practice 2004;54:740-6.

[10] Greuningen M, Heiligers P, Van de Vellden L. Motives for early retirement of self-employed GPs in The Netherlands: a comparison of two time periods. BMC Health Services Research 2012;12(467).

[11] Van Uden C, Glesen P, Metsemakers J, Grol R. Development of out-of-hours primary care by general practitioners (GPs) in The Netherlands: from small-call rotations to large-scale GP cooperatives. International Family Medicine 2006;38(8):565-9.

[12] AMA (Australian Medical Association). Out-of-hours primary medical care. In: AMA position statement. AMA (Australian Medical Association); 2011.

[13] Salisbury C. The demand for out-of-hour care from GPs: a review. Family Practice 2000;17(4):340-7.

[14] Department of Health and Aging. Overview of the National Health Call Centre Network ('the Network'). Canberra: Commonwealth of Australia; 2011. Available at /http://www.health.gov.au/ internet/main/publishing.nsf/Content/national-health-call-centrenetwork-team-overview $\rangle$.

[15] Department of Health and Aging. Round the Clock Medicare - Investing in After Hours GP Services (IAHGPS) Program Program Guidelines, Round 3:2007-2008. Canberra: Commonwealth of Australia; 2006. Available at /http://www.health.gov.au/ internet/main/publishing.nsf/Content/FA3A598B44BFB40DCA2572 C00005443D/\$File/Program\%20Guidelines\%20-\%20Round\%203\%20\%20concluded.pdf (Accessed 16 October 2012).

[16] Department of Health and Aging. Improving primary health care for all Australian. Canberra: Commonwealth of Australia; 2011. Available at 〈http://www.yourHealth.gov.au〉 (Accessed 17 December 2012).

[17] NHCCN (National Health Call Centre Network). Three million callers and counting. In: NHCCN (National Health Call Centre Network) quarterly report. HealthDirect Australia Press Releases; 2012 Available at $\langle$ http://www.healthdirect.org.au/media/press-release (Accessed 6 May 2013).

[18] Department of Health and Aging. Round the Clock Medicare: higher medicare rebates for after-hours GP attendances. Canberra: Department of Health and Aging; 2005. Available at 〈www.health.gov.au/pubs/mbs/index.htm〉 (assessed 11 December 2012).

[19] Department of Health and Aging. Traditional Hours Items 603 and 696 2008. Canberra. Available at http://www.mbsonline.gov. $\mathrm{au} /$ internet/mbsonline/publishing.nsf/Content/News-20081117Transitional-Hours.(Assessed 12 February 2013).

[20] Department of Human services. PIP and SIP data tables Commonwealth Australia 2013. Available at /http://medicarestatistics. humanservices.gov.au/statistics/do.jsp?_PROGRAM=\%2Fstatistics\%2 Fdgp_report_selector\&statisticF=count\&reportTypeFH=report\& variableF $=\&$ drillTypeFH=on $\&$ DIVISIONS $=\& D G P S O R T=\operatorname{divgp} \&$ groupF=999\&schemeF=PIP\&reportNameFH=pipact\&reportFormatF= by +time+period\&reportPeriodF=quarter\&startDateF=201301\&end DateF=201303 $\rangle$ (Accessed 19 January 2015). 
[21] Roxon N. Building a health and hospital network for Australia's future. Australian Labor News 2010. Available at 〈http://www. health.gov.au/internet/ministers/publishing.nst/content/mr-yr10nr-nr088.htm〉 (Accessed 11 December 2012).

[22] Department of Human Service. What's new in PIP. Canberra: Commonwealth of Australia; 2013. Available at 〈http://www. medicareaustralia.gov.au/provider/incentives/pip/updates.jsp.

[23] Kuehnle D, Scott A, Cheng T, Jeon S, Sivey P, Leahy A. Mabel user manual: wave 1 release. Melbourne Institute of Applied Economics and Social Research; 2010.

[24] NAMDS (National after Hours Medical Deputising Service). Understanding after hours medical care in Australia. In: NAMDS paper; 2010.

[25] Thornton J. The labour supply behavior of self-employed solo practice physicians. Applied Economics 1998;30:84-95.

[26] Young R, Leese B, Sibbald B. Imbalances in GP labour market in the UK: evidence from a postal survey and interview with GP leavers. Work, Employment \& Society 2002;14(4):699719.

[27] Sæther E. Physicians' labour supply: the wage impact on hours and practice combinations. Labour 2005;19(4):673-705.
[28] Joyce C, McNeil J, Stoelwinder J. More doctors, but not enough: Australian medical workforce supply 2001-2012. Medical Journal of Australia 2006;184(9):441-6.

[29] Crossley T, Hurley J, Jeon S. Physician labour supply in Canada: a cohort analysis. Health Economics 2009;18:437-56.

[30] Joyce C, Scott A, Jeon H, Humphrey J, Kalb G, Witt J, et al. The "Medicine in Australia: balancing employment and life (MABEL)" longitudinal survey-protocol and baseline data for a prospective cohort study of Australian doctors' workforce participation. BMC Health Services Research 2010;10(50).

[31] Australian Bureau of Statistics. The Australian standard geographical classification (ASGC) remoteness structure. Australian Bureau of Statistics; 2011. Available at /http://www.abs.gov.au/websitedbs/ d3310114.nsf/home/remoteness+structure .

[32] Kamalakanthan A, Jackson S. Doctor supply in Australia: rural-urban imbalances and regulated supply. Australian Journal if Primary Health 2009;15:3-8.

[33] Cheng T, Scott A, Jeon S, Kalb G, Humphreys J, Joyce C. What factors influence the earnings of general practitioners and medical specialists? Evidence from the medicine in Australia: balancing employment and life survey. Health Economics 2012;21:1300-17. 